\title{
Evaluation of Quality of Argentinean Sunflower Oil Used in High-Moisture Food Frying
}

\author{
María Jose Tavera-Quiroz ${ }^{*}$, Adriana Pinotti ${ }^{2,3}$ and Nora Bertola ${ }^{2}$ \\ ${ }^{1}$ Research Group on Innovation and Development of Food Processes, University of Sucre, \\ Sincelejo, Colombia; maria.tavera@unisucre.edu.co \\ ${ }^{2}$ Center for Research and Development in Food Cry technology (CIDCA)- CCT La Plata, CONICET, Faculty of Exact \\ Sciences. National University of La Plata, Buenos Aires, Argentina; adrianapinotti@yahoo.com \\ 3Faculty of Engineering, National University of La Plata, Buenos Aires, Argentina; bertolanora@gmail.com
}

\begin{abstract}
Objective: To make evaluation of quality of Argentinean sunflower oil used in high-moisture food frying through parameters indicators of oil deterioration. Methods: The results were obtained after studying the effect of temperature-time and the type of food subjected to frying through Total Polar Compounds (TPCs) determination. The type of food selected was breaded food and potato chips. From calorimetric analysis (DSC) of frying oil was obtained crystallization temperature and the crystallization enthalpy. Also was determining fatty acid composition of the frying oil by gas chromatography. Findings: It was observed during the oil heating test at various times, that the TPC content increased over time. The highest the temperatures were, the most distinctive the rises were. During the frying of breaded food and potato chips the deterioration of the oil was accelerated, observing the greatest deterioration after the breaded frying process. The thermo grams obtained by DSC showed a well-defined crystallization peak that when heating treatment times were increased, it reflected in lower temperatures and a decrease in enthalpy. A high correlation was found between the concentration of total polar compounds, and the parameters obtained from thermo grams and the concentration of palmitic and linoleic acids. Novelty/Improvement: The results obtained provide useful information for food quality control in order to avoid variations of the sensory and nutritional characteristics of sunflower oil used in high-moisture food frying.
\end{abstract}

Keywords: Frying, High-Moisture Food, Oil, Quality, Total Polar Compounds

\section{Introduction}

The process of frying is considered one of the oldest methods in cooking food, it is used for both, treating food thermally and imparting flavors and textures that are unique to them $\frac{1,2}{2}$. The oil used is decisive in the quality and performance of this process. Argentina is the largest producer of sunflower in South America ${ }^{3}$. Sunflower produces oil rich in linoleic acid and vitamin $\mathrm{E}$ that is very appreciated by domestic consumption over other vegetable oils such as soybean, cottonseed, and rapeseed oils $s^{3}$ informed that in food industry, this product has been used for frying, showing similar performance to other oilseeds such as soybean and canola.
During the frying process, the oil is exposed to atmospheric oxygen and humidity at high temperatures $\left(150-200^{\circ} \mathrm{C}\right)$. These high temperatures and repeated use of the oil increases the susceptibility to thermal and oxidative degradation. Chemical reactions such as hydrolysis, oxidation, and polymerization, lead to decomposition products, such as Free Fatty Acids (FFA), hydroperoxides, surfactants, and hydrocarbons. More than 400 different chemical compounds have been identified in the deterioration of the oil, including 200 volatile products $s^{4}$. Hydrolysis of lipids containing short chain fatty acids produces an unpleasant taste and aroma in the oil, whereas the presence of long chain fatty acids does not produce any perceptible changes in the taste or characteristics of the product. Free Fatty Acids (FFA),

*Author for correspondence 
which appears as a result of hydrolysis, may also undergo oxidation reactions. In the presence of oxygen, peroxides and hydroperoxides are formed, which decompose rapidly to form a variety of products such as aldehydes, ketones, alcohols, among others $\frac{5,6}{}$. The degradation products formed during the frying process include volatile compounds which are partially removed during process, and novel non-volatile compounds which accumulate therein as the process progresses and are incorporated into the food. These compounds possess a higher polarity than unaltered triglycerides and constitute the so-called polar compounds $s^{7.8}$.

There are different standardized analytical methods to evaluate the oil stability as well as the quality and stability of the resulting fried product ${ }^{9,10}$. Some of these methods include rapid analytical indicators such as free acidity; colorimetric methods based on redox indicators, viscosity measurements, and conjugated dienes, electronic noses, among others $\frac{11,12}{}$. The most general analytical method for evaluating the quality of frying oils is the determination of polar compounds which provides an accurate measurement of the percentage of compounds that contain a greater polarity than triglycerides. Most of these are degradation compounds that originated during the process. This method is also the most used in existing regulations to limit the alteration of fry oils and greases, which has been established around $25-27 \%$ as a criterion of deterioration ${ }^{12}$.

The alteration of the grease by frying it also produces a significant increase in its dielectric constant. This technique was introduced in routine practice because of its low cost, quick, solvent free and good correlation with the amount of polar compounds. This advantage adds to the excellent correlation that it presents with the percentages of total polar compounds $\frac{13,14}{}$. There is different equipment, such as the FOS (Food Oil Sensor) or the Test 265 and 270, which can measure changes in the oil's dielectric constant and correlate them with the total polar compound content generated during degradation. Different authors have reported an adequate correlation between the values of the dielectric constant and other alteration parameters for different types of oils $\frac{13,15}{}$ as well as in different temperature conditions and with or without the addition of antioxidants ${ }^{\frac{716,17}{1}}$ observed that the dielectric constant reflects the equilibrium between the polar and non-polar fractions of the frying oil and detected an increasing effect of such constant by increasing moisture, oxidized dimers, and oxidized volatile components ${ }^{18}$ argue the close relationships between percentage in weight of polar compounds and the composition expressed in terms of molar percentages of acyl groups in edible oils heated at frying temperature.

The Differential Scanning Calorimetry (DSC) has been widely used in the investigation of the thermal behavior of consumer products, especially in the food sector. For example, it is used to study the physical behavior during the processing and storage of proteins, carbohydrates, fats and oils. As a result of its advantages in terms of precision and sensitivity, Differential Scanning Calorimetry (DSC) has recently been used to evaluate the quality and stability of fats and oils $s^{7,19,20}$ used the differential scanning calorimetry to study the changes in the thermal properties of commercial oils (sunflower, colza and peanut) during a heat treatment of $10 \mathrm{~h}$ at $180^{\circ} \mathrm{C}$. These authors reported that as the heating time increased, the crystallization peak shifted to lower temperatures and the enthalpy decreased.

The main objective of this study was to evaluate the deterioration kinetics of the quality of the sunflower oil used to fry food. This was achieved by measuring the formation of total polar compounds and other indicators of oil deterioration (parameters obtained by DSC and concentration of palmitic and linoleic acids), studying the effect of temperature, and indicating the type of food subjected to the frying process.

\section{Materials and Methods}

The oil subjected of study was sunflower oil of national origin (Argentina) acquired at the local supermarket. Potato chips and disks of breaded beef of $3.5 \mathrm{~cm}$ in diameter were used as food to fry.

To analyze the effect of the temperature on the oil used in the frying process, the sunflower oil was subjected to heating treatments at different temperatures $\left(150^{\circ} \mathrm{C}\right.$, $180^{\circ} \mathrm{C}$ and $200^{\circ} \mathrm{C}$ ) for a period of 4 hours for the experiments at $180^{\circ}$ and $200^{\circ} \mathrm{C}$ and 7 hours for the experiment at $150^{\circ} \mathrm{C}$. The Total Polar Compounds (TPCs) were measured in the fryer oil for each temperature test, and at predetermined time intervals. Then, a sample was taken for Differential Scanning Calorimetry (DSC) analysis. At the end of the heating process at each temperature, a sample of oil was removed to analyze the fatty acid composition in order to compare it with the composition of the untreated sample. 
In order to study the effect on the deterioration of the oil with different food, potatoes and breaded meat were fired at $180^{\circ} \mathrm{C}$ in successive frying procedures during periods of 3 hours divided in cycles of 45 minutes. In each cycle, 4 groups of approximately 40 grams each of sample food were fried with a waiting time in the oil of 2 minutes per sample group. At the end of each cycle the TPCs were measured. Separate trials were performed for each sample type starting from fresh oil every time.

\subsection{Determination of Total Polar Compounds}

The content of Total Polar Compounds (TPC) was determined with a TESTO 265 capacitive type sensor (Testo Inc., USA). This device measures the dielectric constant of the oil and transforms this value directly into percentage in weight of polar compounds. Measurement is carried out by immersing the sensor in hot oil and provides the $\%$ in weight of polar compounds, together with the temperature.

\subsection{Differential Scanning Calorimetry (DSC)}

The thermo grams were obtained with the DSC Q100 device controlled by a 5000 TA module (TA Instruments, New Castle, Delaware, USA) with a cooling system triggered by an atmosphere of $\mathrm{N}_{2}$ at a flow rate of $20 \mathrm{ml} / \mathrm{min}$. Approximately 7-8 mg of sample oil was weighed into a precision electronic balance in an aluminum capsule and then sealed. Triplicate runs of the frying oil samples were run using an empty aluminum capsule as a reference. The thermo grams were obtained using a cooling program from 10 to $-80^{\circ} \mathrm{C}$ at a rate of $2^{\circ} \mathrm{C} / \mathrm{min}$. From the thermo grams the thermal properties of the frying oil were obtained: $\mathrm{Tc}$, the crystallization temperature $\left({ }^{\circ} \mathrm{C}\right)$ and $\Delta \mathrm{H}$, the crystallization enthalpy $(\mathrm{J} / \mathrm{g})$ calculated as the area under the crystallization peak.

\subsection{Determination of Fatty Acids}

The fatty acid composition was determined by gas chromatography according to the AOAC method 965.4921. First, the glycerides and phospholipids were saponified. Then, the released fatty acids were esterified in the presence of BF 3-methanol and after analyzed by gas chromatography (Agilent Model 6850, Buenos Aires,
Argentina) equipped with a $100 \%$ capillary cyanopropyl silicone column ( SPTM-2340 $60 \mathrm{~m}$ with a $0.32 \mathrm{~mm}$ diameter and $0.25 \mathrm{~mm}$ thick). The oven temperature was set at $140^{\circ} \mathrm{C}$ for 5 minutes and then increased to $220^{\circ} \mathrm{C}$ at $4^{\circ} \mathrm{C}$ per minute. The temperatures of both, the injector and the detector, were $250^{\circ} \mathrm{C}$. The identification of the methyl esters of fatty acids was based on the retention time of the standard esters (Sigma-Aldrich).

\subsection{Statistical Analysis}

All experiments were performed on triplicate samples. Analysis of Variance (ANOVA) was used to analyze the results obtained using the statistical program Info stat v2009 software (Argentina). Comparison of means by Fisher LSD mean was tested, and if $\mathrm{P}<0.05$ the difference was considered statistically significant.

\section{Results and Discussion}

\subsection{Effect of Temperature Treatment on Oil Deterioration}

From the results obtained during the heating of the oil at different times, it was noted that the Total Polar Compound (TPC) content increased with the heating time, this increase being proportional to the temperature value. In other words, the increase was sharper the higher the temperature was. At 4 hours of treatment the TPC content reached values of approximately 15,17 , and $21 \%$ for $150^{\circ}, 180^{\circ}$, and $200^{\circ} \mathrm{C}$ respectively (Figure 1).

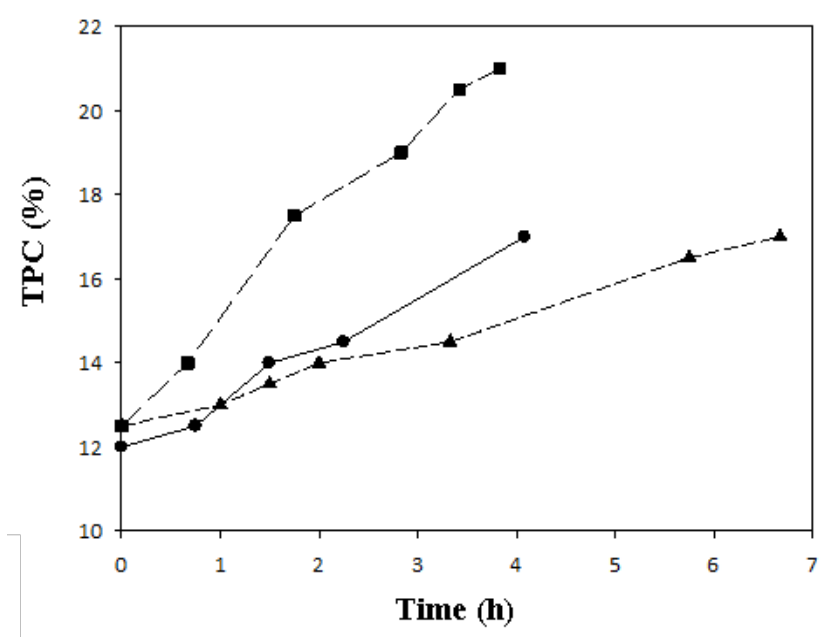

Figure 1. Total polar compounds (\%) formed in the oil during heating treatment at ( $) 150^{\circ},(\bullet) 180^{\circ} \mathrm{y}(\boldsymbol{\square}) 200^{\circ} \mathrm{C}$. 
From the acquired results, zero order kinetics was proposed for the production of total polar compounds at each temperature (Equation (1)).

$$
\frac{d C P T}{d t}=k
$$

Where $\mathrm{k}$ corresponds to the reaction rate constant of TCP formation

Integrating Equation (1) gives the expression:

$$
C P T-\mathrm{CPT}_{0}=k t
$$

Where $\mathrm{TPC}_{0}$ is the concentration of polar compounds at time 0 which corresponds to the time at which the oil reached the heating temperature used.

The mathematical relationship between the reaction rate constant of a chemical reaction and the temperature can be expressed by the Arrhenius equation (Equation (3)):

$$
k=k_{r e f} \exp \left(\frac{E a}{R}\left(\frac{1}{T_{r e f}}-\frac{1}{T}\right)\right)
$$

Where $\mathrm{k}_{\mathrm{ref}}$ is the value of $\mathrm{k}$ for a reference temperature $\left(\mathrm{T}_{\text {ref }}\right), \mathrm{R}$ is the universal gas constant $(8.31 \mathrm{~J} / \mathrm{mol}$ $\mathrm{K})$ and $\mathrm{Ea}$ is the value of the activation energy. A normal procedure to determine $\mathrm{Ea}$ is to linearize Equation (3). This includes, taking logarithms followed by a linear regression of the values of $\mathrm{k}$ as a function of $1 / \mathrm{T}$. But, in this case, the error in determining the value of $\mathrm{Ea}$ is quite large due to the low number of degrees of freedom $\frac{22,23}{t h}$ that considering three temperatures, it would be $\mathrm{n}=3-2=1$. A better way to estimate $\mathrm{Ea}$ is the nonlinear regression of all experimental results at once, since by combining the Equations (2) and (3), it becomes:

$$
C P T=C P T_{0}+k_{r e f} \exp \left(\frac{E a}{R}\left(\frac{1}{T_{r e f}}-\frac{1}{T}\right)\right) t
$$

In this case, the dependent variable is the concentration of total polar compounds while time and temperature are the independent variables. The parameters (constants) to be obtained by non-linear regression are $\mathrm{TCP}_{0}, \mathrm{~K}_{\text {ref }}$ and Ea. For this paper, the average of the temperatures used in the experiments $\left(175^{\circ} \mathrm{C}\right)$ was chosen as the reference temperature. Using this procedure, the number of degrees of freedom was $\mathrm{n}=18-3=15$. Therefore, the simultaneous analysis of all data is clearly preferable to the determination of Ea by linear regression of the values of $k$ as a function of $1 / T$.
Anon-linear regression of the TPC values as a function of time and temperature (Equation (4)) resulted in an Era value of $42.41 \mathrm{~kJ} / \mathrm{mol}$ and a reaction rate constant at $175^{\circ} \mathrm{C}$ (kref) of $1.26 \% \mathrm{TPC} / \mathrm{h}$, with a correlation coefficient $\mathrm{R}=0.979$ (Figure 2). The values of $\mathrm{k}$ for $150^{\circ}, 180^{\circ}$, and $200^{\circ} \mathrm{C}$ were $0.64,1.42$, and $2.30 \% \mathrm{TPC} / \mathrm{h}$ respectively.

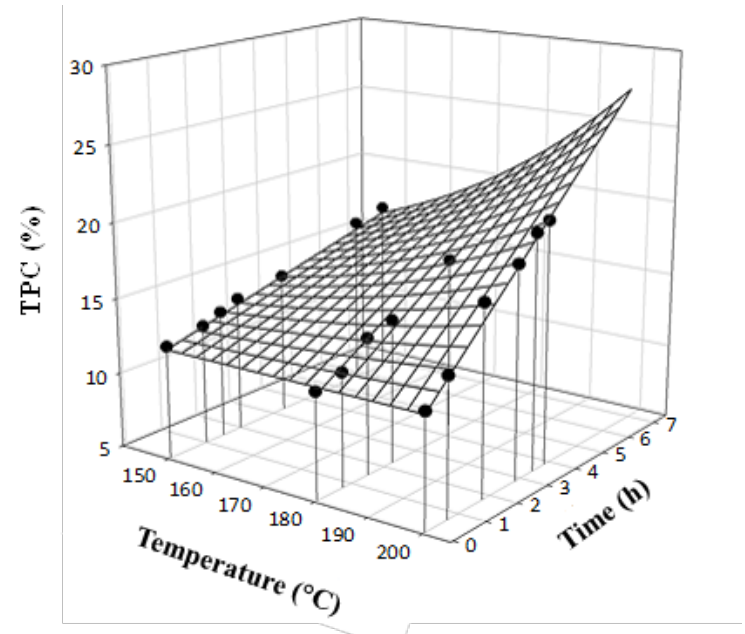

Figure 2. Adjustment of the experimental data of concentration of total polar compounds to the proposed model (Equation (4)).

In the thermo grams obtained by DSC, the fresh sunflower oil showed a crystallization peak at a temperature of $-57.80^{\circ} \mathrm{C}$, with an enthalpy of $34.25 \mathrm{~J} / \mathrm{g}$ (Figure 3 ). For the three heating temperatures observations show that as the heating time increased, the crystallization peak was transferred to lower temperatures and the enthalpy decreased. Figure 4 shows the thermo grams corresponding to oil samples with different heating times at $180^{\circ} \mathrm{C}$. Table 1

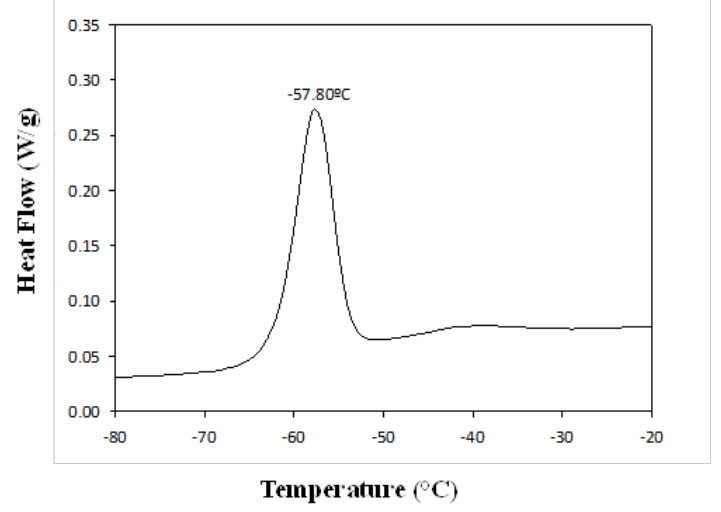

Figure 3. Thermogram of fresh sunflower oil obtained by DSC. 
describes the results of crystallization temperatures and enthalpy values obtained. These results are similar to those obtained by ${ }^{7}$ for soybean oil heated at $180^{\circ} \mathrm{C}$.

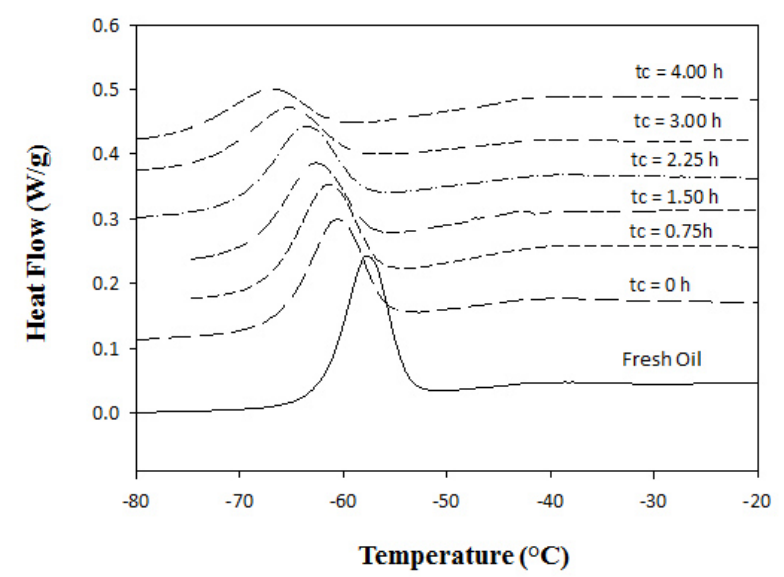

Figure 4. Thermograms obtained for sunflower oil at different heating times at $180^{\circ} \mathrm{C}$. Time 0 corresponds to the heating time at which $\mathrm{T}=180^{\circ} \mathrm{C}$, which was $10 \mathrm{~min}$.

Table 1. Crystallization and enthalpy temperature values during heating of sunflower oil at $180^{\circ} \mathrm{C}$

\begin{tabular}{|c|c|c|}
\hline $\begin{array}{l}\text { Heating Time } \\
(\mathrm{h})\end{array}$ & $\begin{array}{l}\text { Crystallization } \\
\text { Temperature }\left({ }^{\circ} \mathrm{C}\right)\end{array}$ & Enthalpy $(\mathrm{J} / \mathrm{g})$ \\
\hline $0^{\mathrm{a}}$ & -60.71 & 29.30 \\
\hline 0.75 & -61.52 & 28.99 \\
\hline 1.50 & -62.87 & 26.01 \\
\hline 2.25 & -63.75 & 25.38 \\
\hline 3.00 & -65.44 & 21.10 \\
\hline 4.00 & -67.21 & 16.31 \\
\hline
\end{tabular}

aTime 0 corresponds to the heating time at which $\mathrm{T}=180^{\circ} \mathrm{C}$, which was $10 \mathrm{~min}$

For the decrease of the crystallization temperature (Tc) and the enthalpy $(\mathrm{H})$ kinetics of order 0 was proposed. By nonlinear regression of the values of Tc and $\mathrm{H}$, as a function of time and heating temperature (with Equations equivalent to (4)), Ea values of $35.12 \mathrm{~kJ} / \mathrm{mol}$ and $44.76 \mathrm{~kJ} / \mathrm{mol}$ were obtained for the decrease of Tc and $\mathrm{H}$ respectively and are action rate constant at $175^{\circ} \mathrm{C}$ of $-3.74 \mathrm{~J} / \mathrm{gh}$ and $-1.52^{\circ} \mathrm{C} / \mathrm{h}$ with correlation coefficients greater than 0.980 .

Instrumental analysis for TPC has been recognized for international authorities like discarding criteria for used edible oils. This determination is based on changes in dielectric constant and is basically influenced by the presence of moisture in oils ${ }^{24,25}$. Free fatty acids are products from hydrolysis of triglycerides and partly from cleavage and oxidation of fatty acid double bonds ${ }^{26}$. In case of this work this hydrolysis was triggered by the high moisture content of products subjected to frying process. Author in $^{20}$ found that the presence of free fatty acids and oxidation products moved the crystallization peak towards lower temperatures. The reduction of the crystallization enthalpy with heating time can be attributed to the disappearance of triglycerides and the formation of degradation products that do not crystallize within the temperature range analyzed.

The fatty acid composition of the fresh oil is shown in Table 2. The heat treatment of the oil caused an increase in the concentration of palmitic acid (16:0) and a decrease in the concentration of linoleic acid (18:2). Oxidation causes a decrease in the relative percentages of unsaturated fatty acids and an increase in the relative percentages of saturated fatty acids $\frac{27,28}{}$. Therefore, linoleic acid and palmitic acid are generally used as indicators of the degree of deterioration of the oil since linoleic acid is more susceptible to oxidation, whereas palmitic acid is more stable to oxidation $\frac{29,30}{}$.

Table 2. Percent composition of fatty acids in fresh sunflower oil

\begin{tabular}{|l|c|}
\hline Fatty Acids & Relative Percentage \\
\hline Palmític $(16: 0)$ & 5.81 \\
\hline Stearic $(\mathbf{1 8 : 0 )}$ & 3.16 \\
\hline Oleic $(\mathbf{1 8 : 1 )}$ & 22.44 \\
\hline Linoleic $(18: 2)$ & 66.69 \\
\hline Others & 1.90 \\
\hline
\end{tabular}

The concentration of total polar compounds was linearly correlated with the parameters obtained from the thermo grams and the concentration of palmitic and linoleic acids, obtaining correlation coefficients greater than 0.93 (Table 3). The high correlation found between the concentration of total polar compounds and the other measured parameters, suggests the possibility of using any of the analyzed parameters to study the quality of the oils used in the food frying process ${ }^{\underline{7}}$ reported that when the quality of three oils subjected to heating treatment were assessed by DSC, the observed changes in thermal behavior correlated with conventional chemical modifications and the results were used to assess the oxidation status of the oil samples studied similar results were reported by ${ }^{20}$. 
Table 3. Relationship between total polar compound concentration (CPT) and other indicators of oil deterioration $(\mathrm{Tc}=$ Crystallization temperature, $\mathrm{H}=$ enthalpy, 16:0 = Palmitic acid concentration, and 18:2 = Linoleic acid concentration)

\begin{tabular}{|l|c|c|l|}
\hline $\begin{array}{l}\text { Indicator } \\
(\mathrm{Y})\end{array}$ & $\begin{array}{l}\text { Correlation } \\
\text { Coefficient }(\mathrm{R})\end{array}$ & $\begin{array}{l}\text { Number } \\
\text { of Data(n) }\end{array}$ & Equation \\
\hline $\mathrm{Tc}$ & 0.937 & 11 & $\begin{array}{l}\mathrm{Y}=-48.97-1.023 \\
\mathrm{CPT}\end{array}$ \\
\hline $\mathrm{H}$ & 0.962 & 11 & $\mathrm{Y}=66.50-2.86 \mathrm{CPT}$ \\
\hline $\mathbf{1 6 : 0}$ & 0.985 & 4 & $\mathrm{Y}=5.43+0.03 \mathrm{CPT}$ \\
\hline $\mathbf{1 8 : 2}$ & -0.968 & 4 & $\mathrm{Y}=68.18-0.13 \mathrm{CPT}$ \\
\hline
\end{tabular}

\subsection{Effect of the Product Used in the Frying Process on Oil Deterioration}

Oil deterioration was significantly accelerated while the potato chips and the breaded meat were being fried. The formation of polar compounds increased compared to the results from the heat treatment without sample food. The greatest deterioration was observed when the breaded meat discs were fried due to the increase in the residue content of the food in the oil. While at $2.25 \mathrm{~h}$ of heat treatment, the oil reached a TPC content of $14.5 \%$. When potatoes were fried the value was $18.0 \%$, and when breaded meat was used the value obtained was $19.0 \%$ (Figure 5).

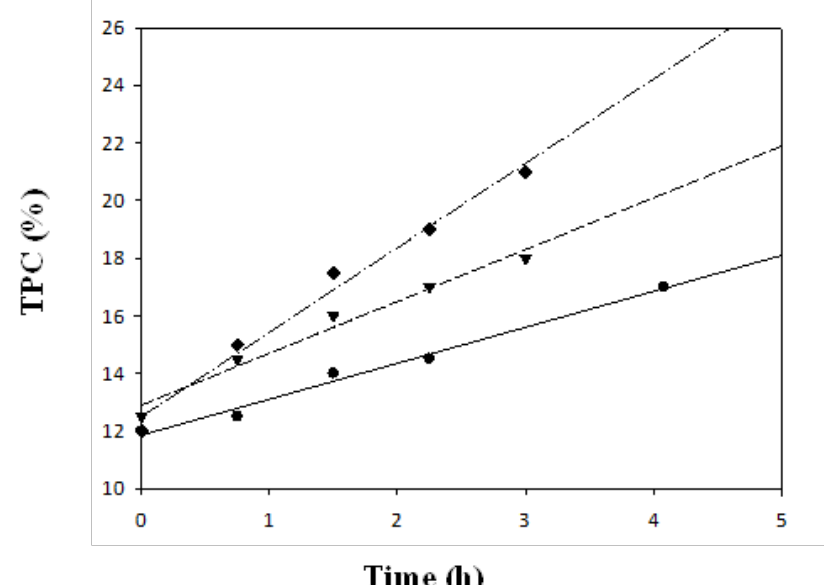

Figure 5. Polar compounds formed during heating of the oil at $180^{\circ} \mathrm{C}(\bullet)$ and during the frying of potatoes $(\boldsymbol{\bullet})$ and breaded meat $(\boldsymbol{\square})$. The symbols correspond to the experimental points and the straight lines to the fit to kinetics of order 0 .
Base on the values found, we calculated the reaction rate constants of polar compounds formation, which were 1.80 and $2.93 \% \mathrm{TPC} / \mathrm{h}$ for the fried potatoes and the fried breaded meat, respectively. In these frying conditions, the oil life (continuous treatment time until TPC $=25 \%$ ) would be 7 hours for frying potato chips (37 fry batches) and 4 hours for breaded meat (21 fry batches). Continuous heating of the oil, after successive frying cycles, caused its degradation by oxidation (catalyzed by temperature, light, metal ions, instauration and oxygen) causing thermo oxidation, hydrolysis and polymerization. These results were similar to obtained by ${ }^{31}$ in cotton oil submitted to frying successive batches of potato chips in a temperature range of $155-195^{\circ} \mathrm{C}$. The deterioration depends on, not only the temperature, but also the duration and the type of frying process, as well as the type of food, according to ${ }^{15}$ in unhydrogenated and partially hydrogenated soybean oils, who concluded that the rate of formation of the degradation compounds is given by the duration, temperature, and degree of hydrogenation of the oil ${ }^{32}$ concluded that heating time and frying cycles increased, all oxidation parameters including acid value, Total Polar Materials (TPM), Conjugated Dienoic Acid (CDA), and p-anisidine values increased significantly in vegetable oils during chicken frying. According to these results, the changes generated in the organoleptic properties of the oil are a limit in the useful life of the oil used was established, which would require the replacement when values of 25-27\% TPC are reached. Establish the degree of oil oxidation can help predict the shelf life of fried foods, protect consumers' health, and optimize the profit of food industries ${ }^{31,32}$.

\section{Conclusions}

The deterioration of the quality of the frying oil was the result of the increase in the heating temperature, the duration of the frying process, and the type of product that was used.

It was established that the deterioration of the frying oil can be modeled with kinetics of order 0 , obtaining the reaction rate constant which increased its value by increasing the heating temperature, which gained the highest value when frying breaded meat samples.

The high correlation found between the concentration of total polar compounds and the parameters obtained from the thermo grams (DSC) and the concentration of palmitic and linoleic acids suggests the possibility of 
using any of the analyzed parameters to study the quality of vegetable oilssubjected to thermal stressing and frying as a quality control to verifying the thermal degradation.

\section{Acknowledgements}

The authors are grateful for the funding provided by the National Council for Scientific and Technical Research (CONICET) in Argentina. We also thank the technical staff member Marina Urriza for her collaboration in the development of laboratory tests.

\section{References}

1. Saguy IS, Dana D. Integrated approach to deep fat frying: Engineering, nutrition, health and consumer aspects. Journal of Food Engineering. 2003; 56(2-3):143-52. Crossref.

2. Bouchon P, Pyle DL. Studying oil absorption in restructured potato chips. Journal of Food Science. 2004; 69(3):115-22.

3. Salas J, Bootello MA, Sunflower GR. Chemistry, Production, Processing, and Utilization. Food uses of sunflower oils. Martínez-Force E, Dunford NT, Salas JJ, editors. Illinois: AOCS Press; 2015. p. 1-730.

4. Moreira RG, Barrufet MA. A new approach to describe oil absorption in fried foods: A simulation study. Journal of Food Engineering. 1998; 35(1):1-22. Crossref.

5. Abdulkarim SM, Frage A, Tan CP, Ghazali HM. Determination of the extent of frying fat deterioration using differential scanning calorimetry. Journal of Food, Agriculture and Environment. 2008; 6:54-9.

6. Jorge N, Soares BBP, Lunardi VM, Malacrida CR. Physicochemical changes of sunflower, corn and soybean oils in fried foods. Quimica Nova. 2005; 28(6):947-51. Crossref.

7. Tan CP, Che Man YB. Differential scanning calorimetric analysis for monitoring the oxidation of heated oils. Food Chemistry. 1999; 67(2):177-84. Crossref.

8. Pangioli P, Melton SL, Collins JL, Panfield MP, Saxton AM. Flavor and storage stability of potato chips fried in cottonseed and sunflower oils and palm olein/sunflower oil blends. Food Chemistry and Toxicology/Journal of Food Science. 2002; 67(1):120-8.

9. Bansal G, Zhou W, Barlow PJ, Joshi P, Neo FL, Lo HL. Evaluation of commercially available rapid test kits for the determination of oil quality in deep-frying operations. Food Chemistry. 2010; 121(2):621-6. Crossref.

10. Taham T, Santos SMD. Evaluation of the quality of sunflower oil subjected to frying processes under controlled conditions. Cientifica. 2017; 45(4):340-6. Crossref.
11. Tomasz M, Wojciech W, Tomasz D, Jacek G, Jacek N. Electronic noses in classification and quality control of edible oils: A review. Food Chemistry. 2018; 246:192-201. Crossref. PMid:29291839

12. Indelicato $\mathrm{S}$, Bongiorno $\mathrm{D}$, Pitonzo $\mathrm{R}$, Di Stefano $\mathrm{V}$, Calabrese V, Indelicato S, Avellone G. Triacylglycerols in edible oils: Determination, characterization, quantitation, chemometric approach and evaluation of adulterations. Journal of Chromatography A. 2017; 1515:1-16. Crossref. PMid:28801042

13. Stier RF. Tests to monitor quality of deep-frying fats and oils. European Journal of Lipid Science and Technology. 2004; 106:766-71. Crossref.

14. Chen WA, Chiu CP, Cheng WC, Hsu CK, Kuo MI. Total polar compounds and acid values of repeatedly used frying oils measured by standard and rapid methods. Journal of Food and Drug Analysis. 2013; 21(1):58-65.

15. Izbaim BF, Moudden A, Taifi N, Aboudaoud I. Evaluation of the performance of frying oils with ultrasonic techniques. Fats and Oils. 2010; 61(2):151-6. Crossref.

16. Perez-Camino MC, Marquez Ruiz G, Dobarganes MC. High performance size exclusion chromatography of polar compounds in heated and non-heated fats. European Journal of Lipid Science and Technology. 1988; 90(8):308-11.

17. Aniołowska M, Kita A. The effect of type of oil and degree of degradation on glycidyl esters content during the frying of French fries. Journal of the American Oil Chemists' Society. 2015; 92(11-12):1621-31. Crossref. PMid:26640279 PMCid:PMC4661204

18. Guillen M, Uriarte PS. Relationships between the evolution of the percentage in weight of polar compounds and that of the molar percentage of acyl groups of edible oils submitted to frying temperature. Food Chemistry. 2013; 138(2-3):1351-4. Crossref. PMid:23411253

19. Solis-Fuentes JA, Amador-Hernandez C, Hernandez-Medel MR, Duran-de-Bazua MC. Physicochemical characterization and thermal behavior of guanabana "almond" oil (Annona muricata, L). Grasas y Aceites. 2010; 61(1):58-66.

20. Gloria H, Aguilera JM. Assessment of the quality of heated oils by differential scanning calorimetry. Journal of Agriculture Food Chemistry. 1998; 46(4):1363-8. Crossref.

21. American oil Chemists' Society (AOCS). Official methods and recommended practices. 5th ed. Champaign: AOCS Press; 1999.

22. Himmelblaum DM. Process analysis by statistical methods. New York: John Wiley and Sons; 1970. p. 1-463.

23. Oteiza JM, Giannuzzi L, Califano AN. Thermal inactivation of Escherichia coli O157:H7 and Escherichia coli isolated from morcilla as affected by composition of the product. Food Research International. 2003; 36(7):703-12. Crossref. 
24. Riera JB, Codony R. Recycled cooking oils: Assessment of risks for public health. European Parliament; 2000. p. 1-100.

25. Ruixue M, Tian G, Lei S, Lin Z, Yun J, Jiaolong L, Xin Z, Feng G, Guanghong Z. Effects of oil-water mixed frying and pure-oil frying on the quality characteristics of soybean oil and chicken chop. Food Science and Technology. 2016; 36(2):329-36, Crossref

26. Aladedunye FA. Curbing thermo-oxidative degradation of frying oils: Current knowledge and challenge. European Journal of Lipid Science and Technology. 2015; 117(11):1867-81. Crossref.

27. Liu HR, White PJ. Oxidative stability of soybean oils with altered fatty acid compositions. Journal American of Oil Chemistry Society. 1992; 69(6):528-32. Crossref.

28. Zhu Y, Li X, Huang J, Zhao C, Qi J, Jin Q, Wang X. Correlations between polycyclic aromatic hydrocarbons and polar components in edible oils during deep frying of peanuts. Food Control. 2018; 87:109-16. Crossref.
29. Li X, Li J, Wang Y, Cao P, Liu Y. Effects of frying oils' fatty acids profile on the formation of polar lipids components and their retention in French fries over deepfrying process. Food Chemistry. 2017; 237:98-105. Crossref. PMid:28764095

30. Houhoula DP, Oreopoulou V, Tzia C. The effect of process time and temperature on the accumulation of polar compounds in cottonseed oil during deep-fat frying. Journal of Science Food and Agricultural. 2003; 83(4):314-9. Crossref.

31. Song J, Kim M-J, Kim Y-J, Lee J. Monitoring changes in acid value, total polar material, and antioxidant vcapacity of oils used for frying chicken. Food Chemistry. 2017; 220:306-12. Crossref. PMid:27855904

32. Bansal G, Zhou W, Barlow PJ, Joshi P, Neo F L, Lo HL. Evaluation of commercially available rapid test kits for the determination of oil quality in deep-frying operations. Food Chemistry. 2010; 121(2):621-6. Crossref. 